\title{
The Opportunities To Have Own Home in Banda Aceh City
}

\author{
Yasrizal $^{1^{*}}$ \\ ${ }^{1}$ Teuku Umar University, Meulaboh, Indonesia
}

\begin{abstract}
As we know that the development of infrastructure, especially housing problems is really needed by everyone and had so much built by developers both inside the city and outside the city. This rmesidential development ranging from the type, design and technical specifications are varied, it is intended to be accessible by consumers. Although developers already provide some conveniences such as the ability to repay in accordance with the selected type, there are still plenty of civil servant (PNS) as well as those working in the private sector has not been able to buy/own their own home on the grounds of various considerations interests respectively. Explanatory variables used in this model consists of a variable income, number of household members, gender, education level, employment sector, age and marital status will affect the probability of households to own their own home.

The data used is the National Socio-Economic Survey 2011, which contains the results of a survey conducted by BPS. This thesis focuses on the area of Banda Aceh as well as using the logit model estimation. The result of calculations show that the proportion of households in the city of Banda Aceh who own their own home around $53.83 \%$, with the proportion who are not self owned approximately 46.17\%. The analysis showed that the variables household size and age significantly affect the chances of having their own home with a significance level of $5 \%$.
\end{abstract}

Keywords: Home Ownership, Logit Model

\section{INTRODUCTION Background}

The need for a home is one of the basic needs (home needs) to humans after food and clothing. House or dwelling is to need humans not only as a residence, but also a place to shelter from external factors (especially natural factors such as wind, rain, sunlight, temperature). In addition to functioning as a protection against natural disasters or weather, the house also has a social role of culture as a family education center, nursery culture, the value of life, preparing the young generation, and as a manifestation of identity. Each individual human being will give priority to the basic needs rather than the needs of the secondary. Similarly, the need for the house, everyone will try to meet the housing needs in every level of public life by observing the tastes and skills.

According to Wie (1978:19-20), the general concept of basic needs standard are common to all states as follows:

* Corresponding author. Email address: yasrizal@utu.ac.id 
1. The personal consumption such as food, clothing and shelter (housing).

2. General services: health, education, water supply, transportation and cultural facilities.

3. Importance of good production, a decent wage for any job so as to meet the needs.

4. Importance of infrastructure that could bring the production and utilization of services (service) in order to meet basic needs.

5. Importance of the participation of all residents over the decisions that have been taken or help provide support for projects relating to the business of equipping staples.

According to Article 5 paragraph (1) of Law no. 4 of 1992 on housing and settlement every citizen has the right to occupy and or enjoy and or have a decent home in a safe environment, safe, harmonious and orderly. Society currently has several options in having a home. The option is to build it yourself or by way of lease, purchase for cash or installment, grants or by other means in accordance with the legislation in force.

Firdaus (1997) explains that the demand is influenced by factors including the location or population growth, income, ease of funding, facilities, and public facilities

According to the Department of Housing and Spatial Planning (Kimtaru, 2004) that housing needs can be basically divided into two main points, namely:

1. Needs home by the trend (tendency) natural population growth.

2. Needs and the provision of home based on the number of appropriate housing.

From the first point above the base line with the needs of the many trends based residential property developer offering a variety of housing types, design and technical specifications who varied, it is intended to be accessible to consumers. Although the developers already provide some conveniences such as the ability to repay in accordance with the selected type, there are still plenty of civil servants (PNS) as well as those working in the private sector has not been able to buy/own their own home on the grounds of various considerations interests respectively.

Indonesia's future needs about 13 million new homes for the community. The data is obtained based on the population census conducted by the Central Statistics Agency (BPS) in the year 2010. So far, the number of housing needs in Indonesia is calculated based on the numbers that have been built by the community and the developers reduced the home uninhabitable and community needs increase every year. In 2004, the estimated number of housing needs in Indonesia reached 7.4 million units. While in 2009 the numbers continue to grow given the housing needs of the community will also continue to increase.

Government Regulation no. 38 of 2007 states that housing is a provincial local government issues and Regency/City. This means that the local government district/municipality became the spearhead of duty to ensure the realization of the house for people, especially the lower middle.

As mandated by the Constitution (Constitution) Amendment 1945 and section $28 \mathrm{H}$ of the 1945 Constitution, that the house is one of the basic rights of the people and therefore every citizen has the right to reside and get a good environment and healthy. But unfortunately the people's civil rights nowadays are still not fully met. One reason is the fulfillment of the housing gap is still relatively 
large. This happens partly because they lack the purchasing power of low-income people, especially in meeting their housing needs.

Tsunami events that occurred in 2004 in Aceh province had brought a lot of change. One impact of the tsunami is the number of residents who lost their homes/dwelling. Banda Aceh city is one of the centers of economic growth is one of the areas affected by the tsunami.

Population growth that occurred in Banda Aceh city either naturally or through the process of urbanization led to a growth in demand for housing. It encourages the growth of residential development in Banda Aceh city good simple house, house type of medium to luxury housing.

Based on BPS data in 2010 the percentage of households living in the house contracts /leases increased to 7.34 percent. This is in line with the decline in household occupying their own house and belongs to the parents/families respectively to 76.59 percent and 10.07 percent. This relates to the appeal of the urban, the many residents who moved to work in urban areas as well as home prices are much more expensive than in rural areas so that they prefer to occupy the house rent/contract due to not being able to buy or build their own homes.

On the basis of the above description it is necessary to conduct a study on how much the probability of a citizen of Banda Aceh to have their own home either because of the influence of income, employment, number of household members, age, marital status, education, and gender.

The Purpose of research

1. Analyzing the characteristics of the household that is income, level of education, status/position in the main job, age, gender, number of household members and marital status that affect the chances of having their own house in Banda Aceh city.

2. Estimating the magnitude of the probability of significant explanatory variables affect the chances of having their own house in Banda Aceh city.

\section{The Benefit of Research}

1. As conceptual contribution for those who want to know the factors that affect the chances of having their own house in Banda Aceh city.

2. As input for the Government of Aceh Province in their policy, and for those who care to improve the welfare of the people so that they can have their own home.

\section{LITERATURE REVIEW}

\section{The Understanding of House}

The house is a typical goods with unique characteristics among all the other items that are used in general. Levy (1995) mentions that the house has the following characteristics:

1. Fixity, which is found in a particular place during the life of the building.

2. Orability, which is generally more durable.

3. Slow rate of technological change, which houses tend to age slower than other goods.

4. Proness to neighborhood effects, the value is affected by the location.

5. Sensitivity to credit, because the house needs a huge expense and often financed with long-term credit. 
6. Speculative motive in ownership, which has the advantage of speculation.

7. Merrid good, the house is seen as something that is selecting beneficial effect that exceeds the user satisfaction.

8. Small scale of production units, when compared with other products.

9. Fragmented ownership, namely ownership separate.

\section{The Chance}

Chance is known also as probability is a way of expressing knowledge or belief that an event has occurred or will apply. This concept has been formulated with more stringent in math, and then used more widely, not only in mathematics and statistics, but also finance, science and philosophy (Ross, 2009).

\section{Descriptive Statistics}

Descriptive statistical is analysis relating to the collection and presentation of data so as to provide useful information. This analysis aims to describe the properties or characteristics of a situation and to make the description or picture of systematic and accurate information on the facts, the properties of the phenomenon under investigation (Walpole, 1993).

\section{Logistic regression}

Logistic regression is used when the response variable is categorical (nominal or ordinal) with continuous predictor variables and categorical (Agresti, 1990).

\section{Study Literatur}

Huang and Clark (2002) in their study of housing onwership choices in Chinese cities transitional using the variables of age and size of households in the form of a continuous variable. The findings of Huang and Clark to the case where the size of China's household as one socio-economic indicators have a positive influence in affecting home ownership.

Hsueh (2000) looked at the relationship between home ownership options with the saving behavior in Taiwan. By using the probit model, Hsueh test the probability determinant community to have a home that is influenced by a number of variables (independent variables). Variable-explanatory variables include: the level of income, age of household head, family size, gender, educational level of the family, marital status of the head of the family, job status of head of the family, as well as the location of the city where the house is located.

Painter (2000) in his study revealed large differences in the level of importance of age, immigrant status, and duration of stay of immigrants as an explanatory variable of home ownership by using a different sample.

\section{THE RESEARCH METHODS}

\section{The Source of Data}

The data used in this study is a secondary data obtained from the National Socioeconomic Survey (SUSENAS) Banda Aceh in 2011. The samples taken as much as 418 households.

Model selection is the type of home ownership is generally characterized by the form of the dependent variable (the dependent variable) which consists of two categories: one's own and do not belong to themselves. Therefore this model is a model we can conclude that the probability of the household see to have their own home by giving it a value of one to have and to give value to zero are not belong to themselves. In the collection of the National Socioeconomic Survey (SUSENAS), there are seven different types of home ownership, which own 
property, contracts, leases, home office, rent-free, the home belonged to the parents/relatives/siblings. Therefore, the modeling will be used in the aggregation type SUSENAS into two with the details as follows: category one has its own house consists of the type of ownership of the property itself, as well as others; zero does not belong to the category itself consists of free rent, home office, home belonging to the parents/relatives/siblings.

Explanatory variables who used in the model consists of several variables. The first explanatory variable is the age of the household head (USI). In this study, the authors will use the variable age in the form of a continuous variable.

Explanatory variables who used in the model consists of several variables. The first explanatory variable is the age to the next explanatory variables are variables Diploma/highest STTB owned household head (PDD). There are 15 categories in SUSENAS Diploma/STTB supreme head of the family owned, which do not have a diploma SD, SD / SDLB, M. Elementary, Package A, SMP/SMPLB, M. Tsanawiyah, Package B, SMA/SMLB, M. Aliyah, SMK, Package C, D1/D2, D3/Bachelor, D4/S1, and S2/S3.pala households (USI). In this study, the authors will use the variable age in the form of a continuous variable.

Another variable used is the number of household members (ART) in one household. In addition, the marital status of the household head was put into this model. The categories of marital status (STA) in SUSENAS consists of 4 categories: not married, married, divorced and divorced to die.

Variable employment status of household head was included in the model to describe the condition of the welfare of the household head. Employment status of workers (PEK) is organized into discrete variables by category on their own, trying assisted by temporary workers/laborers are not paid, trying to help keep workers/laborers are paid, and free workers or unpaid family workers.

Other continuous variables were income level families (PDP). The author uses a variable expenditure per capita.

In general, home ownership model itself that will be tested are as follows:

$\operatorname{Prob}(\mathrm{Y}=\mathrm{own}=1)=\alpha_{0}+\alpha_{1}{ }^{*} \mathrm{ART}+\alpha_{2}{ }^{*} \mathrm{KEL}+\alpha_{3}{ }^{*} \mathrm{STA}+\alpha_{4}{ }^{*} \mathrm{PDD}+\alpha_{5}{ }^{*} \mathrm{USI}+\alpha_{6}{ }^{*} \mathrm{PEK}$ $+\alpha_{7}^{*} \mathrm{PDP}$

\section{RESULTS AND DISCUSSION}

4.1 Characteristics of Households

Every household has different traits and characteristics of both the general characteristics of the household and individual characteristics of the household head. Some of these characteristics may provide different implications for home ownership.

4.1.1. Number of Household Members

The first variable that affects the chances of having their own house in Banda Aceh city is the number of household members has a positive effect on the chances of their own homes that the larger the household size will increase the probability of households to occupy his own house. It is not separated from the need to accommodate the size of the household members. On average, members of urban households in Indonesia amounted to 4.06 household members for each household. By region, the households urban in Sumatra has an average number of household members most. 
Each increase of one member of the household will increase the probability of households in Banda Aceh city to have their own home at $3.49 \%$.

The findings of this positive relationship was also found by Huang and Clark (2002) for the case where the size of China's household as one of the socioeconomic indicators have a positive influence in affecting home ownership.

Of samples used in this study, it appears that the average number of household members to the status of one's own home instead of having a smaller number (the average number of ART $=3$ ) compared with households that have their own home (average number of ART average $=4$ ). Based on this it can be concluded that the number of households that have household members who have fewer greater tendency to occupy the house does not belong to its own compared to the number of household members of a larger household (see Table 1).

Table 1 Ownership Home Based Number of Household Members

\section{Home Ownership Number of Household Members}

(Mean)

\begin{tabular}{ll}
\hline 1. Owned itself & 4 \\
\hline 2.'s Not one's own & 3 \\
\hline
\end{tabular}

\subsubsection{Education}

The next is the interesting findings of the study variables. The estimation results indicate that the estimated coefficients have a negative sign, so that the face would be interpreted that any increase in education head of the family, will lead to the probability of the household to occupy the house itself is reduced.

A fact which tends to the opposite of the hypothesis that education will be built directly proportional to the probability of households to have their own home can be described below. From the calculation of the sample used descriptive statistics, households that have seen the highest high school diploma with home ownership status is equal to zero (not the property itself) was $53.1 \%$, while households with home ownership status is equal to one (self) of $46.9 \%$. Seen that the head of household with a high school education who have their own home and the head of household and have a high school education is not one's own home is not too much different, so that it does not cause is too the influence of the educational level (see Table 2).

Table 2 Ownership Top Home Based Diploma Owned

\begin{tabular}{llcc}
\hline \multirow{2}{*}{ Top diploma Owned } & \multicolumn{2}{c}{ Home Ownership } \\
\cline { 2 - 3 } & Own Alone (\%) & Not Own Alone (\%) \\
\hline 1. No have a diploma of SD & 77,3 & 22,7 \\
2. SD/SDLB & 65,4 & 34,6 \\
3. M. Ibtidaiyah & 100 & 0 \\
4. Packet A & 0 & 0 \\
5. SMP/SMPLB & 64,4 & 35,6 \\
6. M. Tsanawiyah & 50,0 & 50,0 \\
7. Packet B & 0 & 0 \\
8. SMA/SMLB & 46,9 & 53,1 \\
9. M. Aliyah & 33,3 & 66,7 \\
10. SMK & 65,6 & 34,4 \\
\hline
\end{tabular}




\begin{tabular}{lcc}
\hline \multirow{2}{*}{ Top diploma Owned } & \multicolumn{2}{c}{ Home Ownership } \\
\cline { 2 - 3 } & Own Alone (\%) & Not Own Alone (\%) \\
\hline 11. Packet C & 0 & 100 \\
12. D1/D2 & 33,3 & 66,7 \\
13. D3/ baccalaureate & 45,5 & 54,5 \\
14. D4/S1 & 45,7 & 54,3 \\
15. S2/S3 & 84,6 & 15,4 \\
\hline
\end{tabular}

Source: BPS, SUSENAS 2011 (processed)

\subsubsection{Marital Status}

The next variables that also affect the household to determine the probability of having their own home is the marital status of household head. From the estimation results indicate that marital status does not affect the opportunity to have their own home. Judging from the data sample of respondents that I use, the sample of respondents on average are in the coastal areas, where most of the respondents were victims of the tsunami that gets home help.

\subsubsection{Employment Status}

Employment status did not significantly affect the probability of households to occupy his own house. This leads to the status of workers who work in the informal sector has a relatively low level of income. The income level of patriarch working to the status of self-employed workers have a relatively low income levels. With these low revenue resulting huge obstacle for households to have their own home.

\subsubsection{Gender}

The estimation results of gender variables significantly affect the chances of having their own home, based on descriptive statistics of household heads of men who own their own home by $53.1 \%$ while the female head of household was $59.6 \%$. The difference is not too much different that the gender variable does not affect the chance to own their own home (see Table 3 ).

Table 3 Home Ownership by Gender

\begin{tabular}{lcc}
\hline \multirow{2}{*}{ Gender } & \multicolumn{2}{c}{ Kepemilikan Rumah } \\
& Own Alone (\%) & Not Own Alone (\%) \\
\hline 1. Man & 53,1 & 59,6 \\
2. Woman & 46,9 & 40,4 \\
\hline
\end{tabular}

Source: BPS, SUSENAS 2011 (processed)

\subsubsection{Age of Household Patriarch}

The estimation results of the variable age of household head affects the chances of having their own home, based on descriptive statistics the average age of household heads who have their own home is 45 years (see Table 4). Each additional 1 year of age of household head, then the probability to have their own home will also increase by $1.16 \%$. 
Table 4 Home Ownership by Age

\begin{tabular}{clc}
\hline & Home Ownership & Age (Mean) \\
No & & \\
\hline 1 & Not Own Alone & 37 \\
\hline 2 & Own Alone & 45 \\
\hline & Source: BPS, SUSENAS 2011 (processed)
\end{tabular}

\subsubsection{The. Income}

The final variable that affects the probability of households to have their own home is the household income. In this study, the authors use a month per capita expenditure. From the estimation of these variables did not significantly affect the chance of having their own home. Based on the descriptive statistics of household head men spending an average of Rp.1.521.851 while female-headed households spending an average of Rp. 1,423,116.

Table 5 Expenditure Per Capita month by Gender

\begin{tabular}{lc}
\hline Gender & Expenditure Per Capita month \\
\hline Man & 1.521 .851 \\
\hline Woman & 1.423 .116 \\
\hline \multicolumn{2}{c}{ Source: BPS, SUSENAS 2011 (processed) }
\end{tabular}

\subsection{The Estimation Results}

Based on estimates by the software " $\mathrm{R}$ " is obtained that the explanatory variables that significantly affect the chances of having your own home is the household size and age of the household head. The Probability of both variables are:

Table 6 Probability of Number of Household Members

\begin{tabular}{cc}
\hline $\begin{array}{c}\text { The Number of } \\
\text { Household Members }\end{array}$ & Probability \\
\hline 1 & 0,45 \\
2 & 0,48 \\
3 & 0,52 \\
4 & 0,55 \\
5 & 0,59 \\
6 & 0,62 \\
7 & 0,65 \\
8 & 0,68 \\
9 & 0,71 \\
10 & 0,74
\end{tabular}

Source: BPS, SUSENAS 2011 (processed)

The estimation results of the variable number of household members showed that every increase of one (1) member of the household then the probability of having their own home was also up by 0.03 . 
An overview of the number of household members on the probability to have their own home is shown in Figure 1.

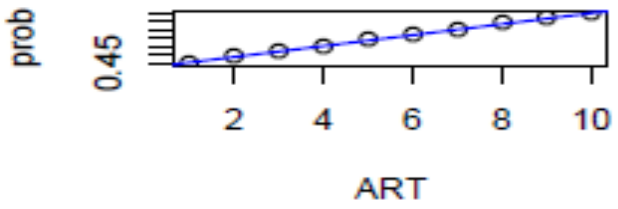

Figure 1 Plot of Number of Household Members to Probability

Table 7 Probability of Age of Household Patriarch

\begin{tabular}{|c|c|c|c|c|c|}
\hline Age & Probability & Age & Probability & Age & Probability \\
\hline 19 & 0,18 & 37 & 0,46 & 55 & 0,77 \\
20 & 0,19 & 38 & 0,48 & 56 & 0,78 \\
21 & 0.21 & 39 & 0,50 & 57 & 0,79 \\
22 & 0,22 & 40 & 0,52 & 58 & 0,80 \\
23 & 0,23 & 41 & 0,54 & 59 & 0,82 \\
24 & 0,25 & 42 & 0,56 & 60 & 0,83 \\
25 & 0,26 & 43 & 0,58 & 61 & 0,84 \\
26 & 0,27 & 44 & 0,59 & 62 & 0,85 \\
27 & 0,29 & 45 & 0,61 & 63 & 0,86 \\
28 & 0,31 & 46 & 0,63 & 64 & 0,86 \\
29 & 0.32 & 47 & 0,65 & 65 & 0,87 \\
30 & 0.34 & 48 & 0,66 & 66 & 0,88 \\
31 & 0,36 & 49 & 0,68 & 67 & 0,89 \\
32 & 0,37 & 50 & 0,69 & 69 & 0,90 \\
33 & 0,39 & 51 & 0,71 & 70 & 0,91 \\
34 & 0,41 & 52 & 0,73 & 72 & 0,92 \\
35 & 0,43 & 53 & 0,74 & 73 & 0,92 \\
36 & 0,45 & 54 & 0,75 & 75 & 0,93 \\
\hline
\end{tabular}

The results of the estimation of age of household head shows that each increase of 1 (one) year of age of household head, then the probability to have their own home also rose by 0.01 . An overview of the age of the head of household on the probability of having their own home is shown in Figure 2.

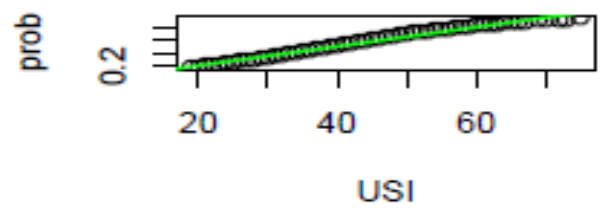

Figure 2 Plot of the Household Head Age Probability

For Figure 3 through Figure 5 is a free variable that does not significantly affect the chances of having their own home, although it appears that the 
relationship between the dependent variable with the independent variable is a linear positive and linear negative (can be represented by a straight line). Insignificant variables gender, marital status, education, employment status of the opportunity to have their own home due to the sample of respondents is tsunami victims who live in coastal areas, which according to the author of the respondents had to get home help.

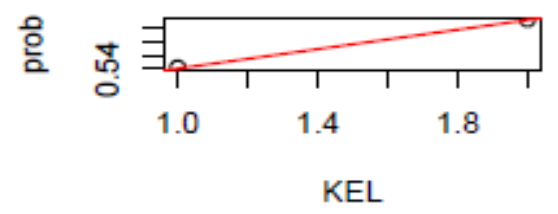

Figure 3 Plot Gender of Household Patriarch of the Probability

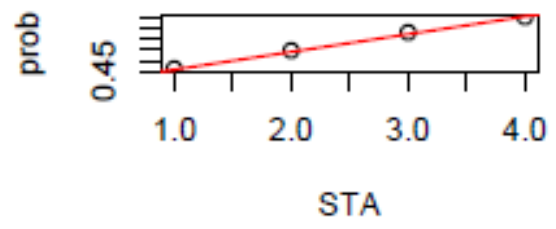

Figure 4 Plot Marital Status of Household Patriarch of the Probability

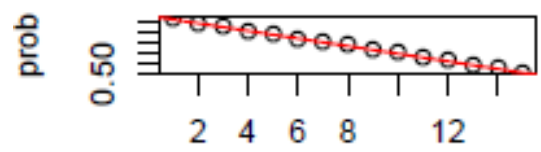

PDD

Figure 5 Plot of Education of Household Patriarch to Probability

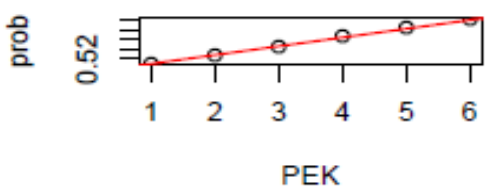

Figure 6 Plot Employment Status of Household Patriarch of the Probability

\section{CONCLUSIONS AND SUGGESTION}

Based on the findings that have been presented, there are a number of conclusions that can be drawn from the explanations that have been submitted. Systematically, some conclusions from this study include:

a. The estimation results indicate that the number of household members in a positive effect on the probability of households to have their own home. Each 
member of an increase in one person households will increase the probability of households to have their own home at $3.49 \%$ with the other variables held constant.

b. Age of the household head has a significant effect on probability in own home. From the results of the estimation indicate each by an additional 1 year of age will increase the probability of households to have their own home by $1.16 \%$ with the other variables held constant. Gender of household head based on the estimation does not significantly affect the chances of having their own home. Descriptive statistics show the head of the household men who have their own home by $53.1 \%$ and female heads of households who have their own home by $46.9 \%$. This illustrates that gender does not indicate the magnitude of the opportunity to have their own home, because of the difference in ownership of $6.2 \%$.

c. Descriptive statistics heads of household marital status married/have ever been married have their own home by $94.7 \%$ while the unmarried have their own homes by $5.3 \%$. Judging from the difference in home ownership there is great variation marital status should not significantly affect the ownership of the house itself. However, based on the estimates can be things that do not fit. This is according to the author because the sample of respondents living in coastal areas are victims tsunami that have received housing aid.

d. The variable education of household head, household head employment status and employment status of household head also does not significantly affect the chances of having their own home, it is also due to the sample of respondents residing in coastal areas is tsunami victims who received home help.

\section{SUGGESTION}

- Data household sample used is a cross section so that the observations were made over a period of time. This weakness gives suggestion to the government, especially the BPS in order to provide a more survey panel data so that each household behavior over time can be analyzed.

- Further research on the opportunity to have their own home can use other variables that have not been covered in this study.

\section{References}

Firdaus, A. (1997). Analisis Pengaruh Jarak ke Jalan Lingkar Luar terhadap Nilai Jual Properti Perumahan di Kecamatan Depok Sleman Yogyakarta. Jurnal Survey dan Penilaian, 1. Jakarta.

Agresti, A. (1990). Catagorical Data Analysis. Canada: John Wiley \& Sons.

Hsueh, L. M. (2000). The Relationship between Housing Price, Tenure Choice and Saving Behavior in Taiwan. International Real Estate Review, 3(1), 11 - 33.

Huang, Y., \& Clark, W. A.V. (2002). Housing Tenure Choice in Transitional Urban China: a Multival Analysis. Urban Studies, 39(1), 7 - 32. 
AFEBI Islamic Finance and Economic Review (AIFER)

Vol.02 No.01, June 2017

Painter, G. (2000). Tenure Choice with Sample Selection: Differences among Alternative Samples. Journal of Housing Economics, 9, 197 - 213.

Ross, S.M. (2009). A First Course In Probability. Prentice Hall.

Wie, T.K. (1978). From Growth to Basic Needs. Jakarta: Leknas LIPI. 